The Open Materials Science Journal
CrossMark
Content list available at: www.benthamopen.com/TOMSJ/
DOI: $10.2174 / 1874088 \mathrm{X} 01711010022$

RESEARCH ARTICLE

\title{
Preparation and Physical Performance of Green Poly(L-lactic acid) Composition by Blending with Starch
}

\author{
Yan-Hua Cai", Qian Zheng and Wen-Jiang Guo \\ Chongqing Key Laboratory of Environmental Materials \& Remediation Technologies, Chongqing University of Arts \\ and Sciences, Yongchuan, Chongqing-402160, P.R. China
}

Received: February 23, 2017

Revised: March 03, 2017

Accepted: May 24, 2017

\begin{abstract}
:
Objective:

To develop more green polymer composites and further know the performance of green composites, the composites based on green poly(L-lactic acid) (PLLA) and starch were fabricated by a counter-rotating mixer. And effect of starch on the fluidity and nucleating performance of PLLA was investigated using melt index instrument, optical depolarizer and wide angle X-ray diffraction instrument, respectively.
\end{abstract}

\section{Method and Conclusion:}

The fluidity of PLLA/starch composites showed that, compared to the neat PLLA, the addition of starch made the fluidity of PLLA increase significantly and the melt mass flow rate of PLLA $/ 5 \%$ starch sample had the maximum value $13.36 \mathrm{~g} / 10 \mathrm{~min}$. In addition, the introduction of starch could also increase the crystallization rate of PLLA through isothermal crystallization measurement and x-ray diffraction analysis, the maximum value of crystallization rate of PLLA/starch composites appeared in low crystallization temperature zone, and $10 \mathrm{wt} \%$ starch could make the t1/2 of PLLA decrease from $3999.4 \mathrm{~s}$ to $421.4 \mathrm{~s}$.

Keywords: Poly(L-lactic acid), Starch, Green composites, Nucleating performance, Fluidity, Crystalization.

\section{INTRODUCTION}

It is well-known that Poly(L-lactic acid) (PLLA) is a very typical green thermoplastic polymer, and there exists many advantages such as biodegradable performance, biocompatibility, easy process, etc [1]. Thus, an increasing number of studies results based on PLLA were reported by scientists, and PLLA has been identified as a leader of biodegradable polymer materials. However, there are still some disadvantages to restrict the growing application of PLLA in industry and agriculture. Especially, materials based on PLLA often need to be modified by addition of functional additives to meet different application requirements. For example, Xiong et al. [2] introduced starch with surface hydrophobic modification using epoxidized itaconic acid or epoxidized cardanol to improve mechanical and thermal properties of PLA. The addition of modification starch made the tensile strength of PLA increase from about 35 $\mathrm{MPa}$ to over $50 \mathrm{MPa}$, and the crystallization ability of PLA was enhanced significantly. In order to reinforce the ultraviolet-resistance properties of PLA to meet outdoor application requirement, nanosilver was introduced into PLA to promote the ultraviolet-resistance properties and study the photochemical degradation. The experimental results showed that the neat PLA was more sensitive to photodegradation than PLA/nanosilver composites [3].

Starch is another important polymer material. Similarly, biodegradability is a significant feature of starch as PLLA. Many literatures have reported that starch can be added into thermoplastic polymer to improve the performance of polymers [4, 5]. Witono et al. investigated the water absorption and retention characteristics of cassava starch grafted

\footnotetext{
* Address correspondence to this author at the Chongqing Key Laboratory of Environmental Materials \& Remediation Technologies, Chongqing University of Arts and Sciences, Yongchuan, Chongqing-402160, P.R. China, Tel: ???; E-mail: caiyh651@aliyun.com
} 
with polyacrylic acid. The results showed that starch grafted with polyacrylic acid possessed very good initial absorption capacity, and this material could retain up to $63 \mathrm{~g} \mathrm{H}_{2} \mathrm{O} / \mathrm{g}$ under severe suction. The absorption kinetics indicated that polymer chain relaxations determined the rate of water penetration into the gel [6]. Though there existed many advantages of blending two different polymers, a few polymers were miscible with each other. Ferrira et al. added organoclay into polymer to improve the compatibility of blending materials; their experiment results indicated that the organoclay could significantly improve the compatibility between plasticized starch and polypropylene [7]. In addition, the literature reported that the starch also improves the hydrophilicity of PLA/starch/chitosan blends with antimicrobial function [8].

Both PLA and starch are very promising polymer materials, moreover, there is no doubt that PLA/starch blend materials should have more advantages. To further know more about performance of PLA/starch materials, in this paper, 2002D PLLA, purchased from Nature Works LLC and having $M_{w}$ as $1.95 \cdot 10^{5}$, with different starch content blend materials were fabricated using melt blending technology. The thermal performance and fluidity of PLLA/starch composites were evaluated.

\section{EXPERIMENT}

\subsection{Preparation of PLLA/Starch Composites}

Blending of PLLA and starch dried in a vacuum oven for $48 \mathrm{~h}$ was performed on a counter-rotating mixer, and the similar details of the preparation process of PLLA/starch composites were described in our earlier work $[9,10]$.

\subsection{Testing}

Wide angle X-ray diffraction (WAXD): WAXD measurement of PLA/starch composites after different heating treatments was performed on a diffractometer (D/MAX2550, Rigaku, Japan) using $\mathrm{Cu} K_{\alpha}$ radiation (wavelength, 1.54 $\AA$ ) in the range of $2 \theta=10-80^{\circ}$ with the scanning rate of $2 \% \mathrm{~min}$.

Crystallization Measurement: Crystallization of PLLA/starch composites was investigated by GJY-IIIoptical depolarizer (Donghuang University, China) in the region from $100{ }^{\circ} \mathrm{C}$ to $120{ }^{\circ} \mathrm{C}$.

Melt Index: The melt index instrument (Beijing Guance Testing Instrument Co., LTD, China) was used to measure the fluidity of melting PLLA/starch composites. The measurement parameters are as follows: the measurement temperature was $150{ }^{\circ} \mathrm{C}$, and the load was $10 \mathrm{Kg}$.

\section{RESULTS AND DISCUSSION}

\subsection{Fluidity of PLLA/Starch Composites}

The fluidity of PLLA/starch composites was measured using melt index instrument, and the results are shown in (Fig. 1). As shown in (Fig. 1), the melt mass flow rate (MFR) of the neat PLLA is slow, which indicates that the fluidity of the neat PLLA is poor at $150{ }^{\circ} \mathrm{C}$; the possible reason is that the low measurement temperature makes the fluidity of the neat PLLA poor. However, the data of (Fig. 1) shows that addition of starch makes the fluidity of PLLA significantly increased, especially upon the $5 \mathrm{wt} \%$ starch, the MFR of PLLA/starch composites has the maximum value of $13.36 \mathrm{~g} / 10 \mathrm{~min}$. Then, the value begins becoming small. This result indicates that $5 \mathrm{wt} \% \mathrm{starch}$ makes the PLLA have the best fluidity, and the reason is that the starch would contribute to the fluidity of PLLA improvement, but too much starch also would block the movement of PLLA which affects the fluidity of PLLA. In addition, it is clear from (Fig. 1) that the fluidity of PLLA/starch is better than that of PLLA at low temperature, which indicates that addition of starch would be effective to avoid the degradation of PLLA and additives with low decomposition temperature because of high processing temperature, and widen the application field of PLLA materials.

\subsection{Crystallization of PLLA/Starch Composites}

Influence of starch on the crystallization of PLA had been reported in literature $[11,12]$, and the research results showed that starch could serve as nucleating agent of PLA, improving the degree of crystallization and crystallization rate of PLLA. Similarly, the crystallization performance of PLLA with starch was investigated using optical depolarizer, and the rate of measurement is shown in (Fig. 2). It is observed that the half-time of overall crystallization $t_{1 / 2}$ of PLLA is long, and the crystallization rate of neat PLLA appears to be maximum at value $115^{\circ} \mathrm{C}$. However, the addition of starch can increase the crystallization rate; this result is consistent with other literatures results [11, 12]. It is 
worth noting that the maximum value of crystallization rate of PLLA/starch composites appears in low crystallization temperature zone. This phenomenon suggests that the crystallization of PLLA/starch composites is significantly affected by starch and crystallization temperature, and the addition of starch makes the optimization crystallization temperature shift to low temperature zone. Compared to the neat PLLA, $10 \%$ starch can make the $t_{1 / 2}$ of PLLA decrease from $3999.4 \mathrm{~s}$ to $421.4 \mathrm{~s}$.

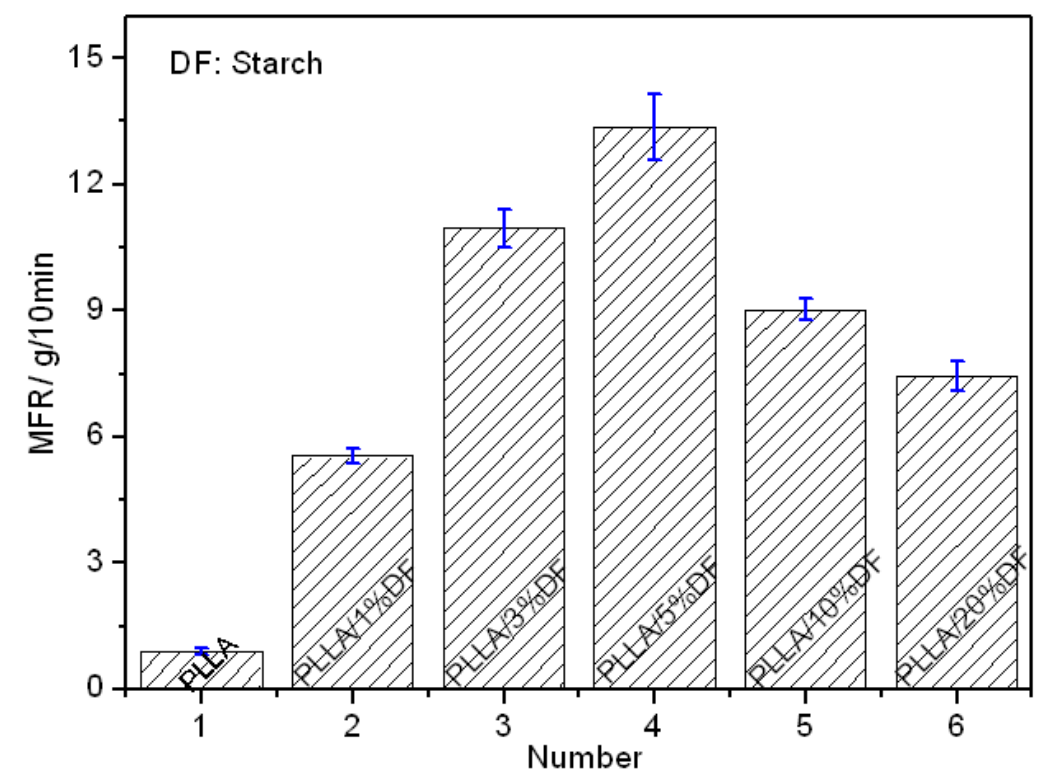

Fig. (1). The fluidity of PLLA/starch composites at $150{ }^{\circ} \mathrm{C}$.

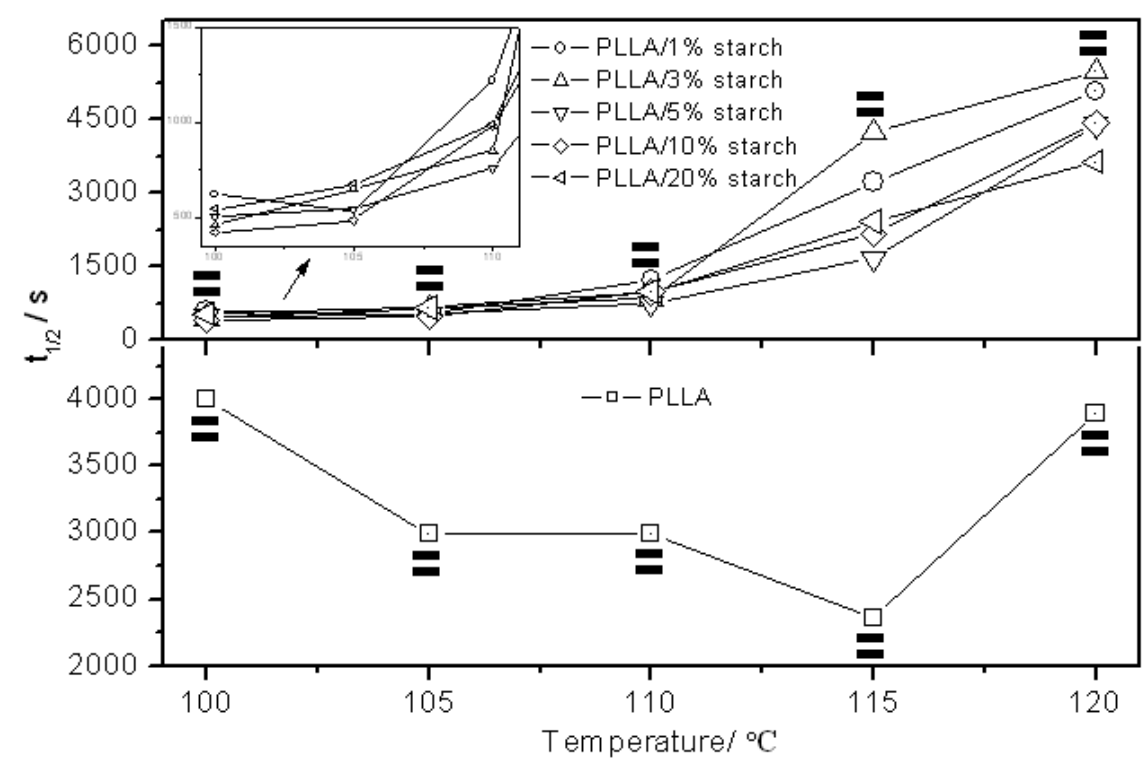

Fig. (2). The effect of temperature and starch on crystallization of PLLA.

Meantime, Avrami equation is used to describe the kinetics of crystallization behavior of PLLA/starch composites, and the Avrami plots of PLLA/starch composites are shown in Fig. (3); it is clear from Fig. (3) that the relationship of $\log \left[-\ln \left(1-\mathrm{X}_{\mathrm{t}}\right)\right]$ versus logt is linear, which indicates that Avrami equation may be feasible to describe the crystallization behavior of PLLA/starch composites.

In addition, the crystallization of PLLA/starch composites was also investigated by WAXD. Fig. (4) shows the XRD curves of PLLA and PLLA/starch samples without heating treatment, in which it can be observed that the trend of XRD curves of PLLA and PLLA with different starch contents is similar, and the peaks are very wide, which indicates 
that the degree of crystallization of all samples is low, and this low degree of crystallization results from rapid cooling molding.
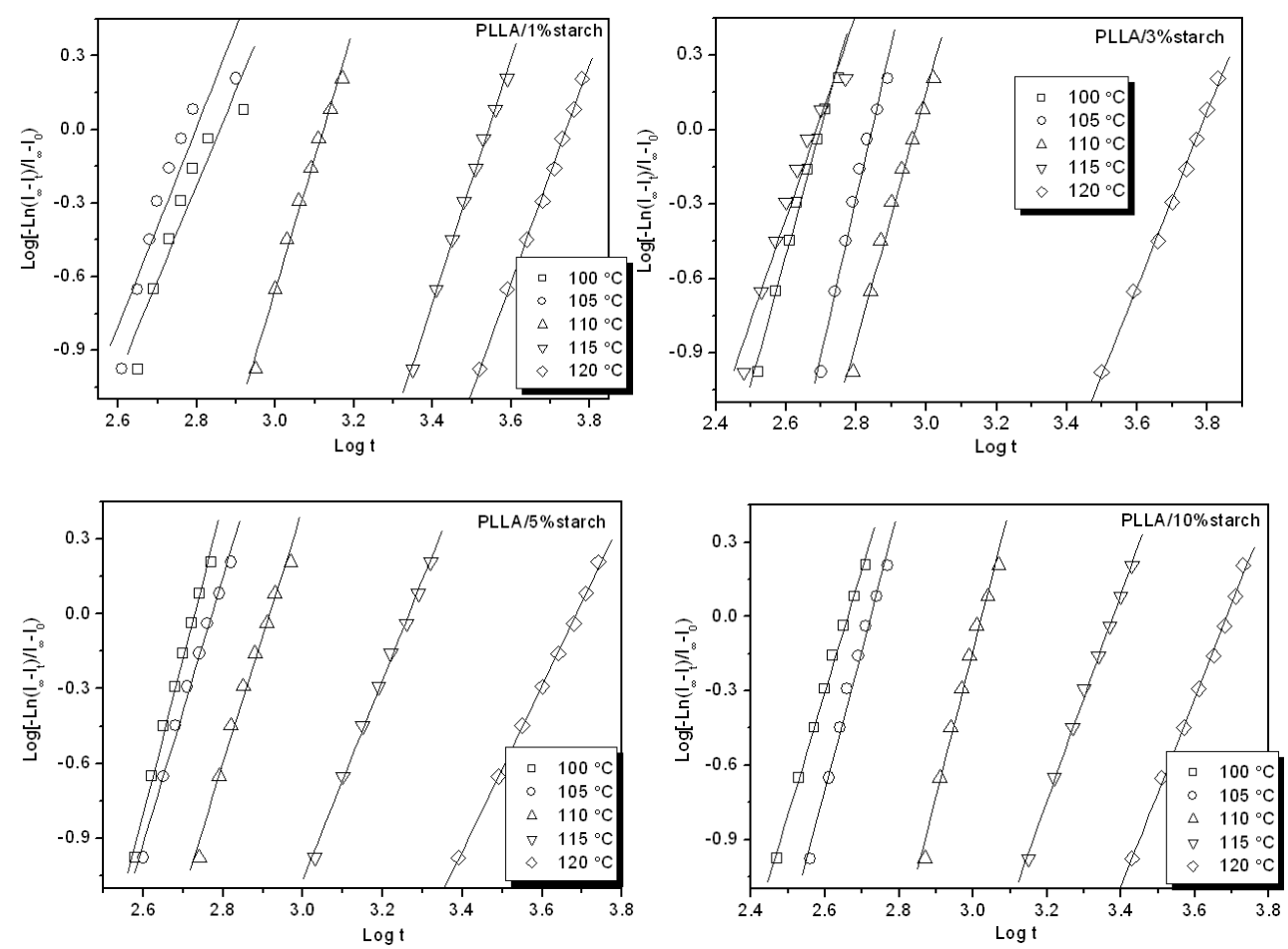

Fig. (3). Avrami plots for PLLA/starch composites at different temperature.

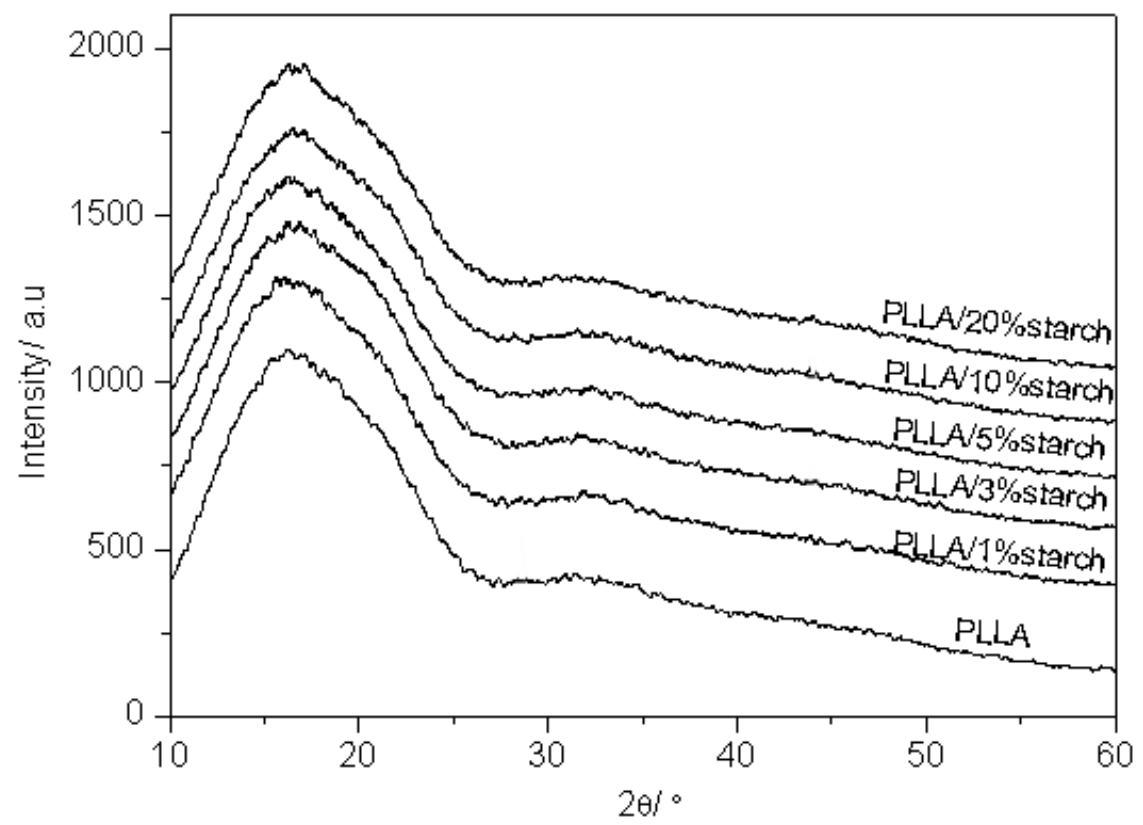

Fig. (4). XRD curves of PLLA and PLLA/starch without heating treatment.

However, the XRD curves of PLLA and PLLA/starch after isothermal crystallization at $100{ }^{\circ} \mathrm{C}$ for 5 min are very different. As shown in Fig. (5), the neat PLLA only exhibits a peak at $2 \theta=16.6^{\circ}$ due to diffraction from (110) plane, and the intensity of (110) plane diffraction peak is very weak. These results indicate that the crystal of the neat PLLA after isothermal crystallization at $100^{\circ} \mathrm{C}$ for $5 \mathrm{~min}$ is not perfect. However, all PLLA/starch samples exhibit peaks not only at $2 \theta=16.6^{\circ}$, but also at $2 \theta=14.7^{\circ}, 18.9^{\circ}$ and $22.2^{\circ}$ occurring from the (010) plane, (203) plane and (205) plane, 
respectively [13].Moreover, the intensity of diffraction peak is very strong, resulting from the nucleating effect of starch. With increasing of crystallization time, it is clear from Fig. (6) that the diffraction peak of the neat PLLA further strengthens because of increasing crystal perfection of the neat PLLA. However, compared to the diffraction peaks of PLLA/starch after isothermal crystallization at $100{ }^{\circ} \mathrm{C}$ for $5 \mathrm{~min}$, the diffraction peaks of PLLA/starch composites after isothermal crystallization at $100^{\circ} \mathrm{C}$ for $15 \mathrm{~min}$ strengthen slightly, which indicates that the crystal of PLLA/starch after isothermal crystallization at $100^{\circ} \mathrm{C}$ for $5 \mathrm{~min}$ has become relatively perfect.

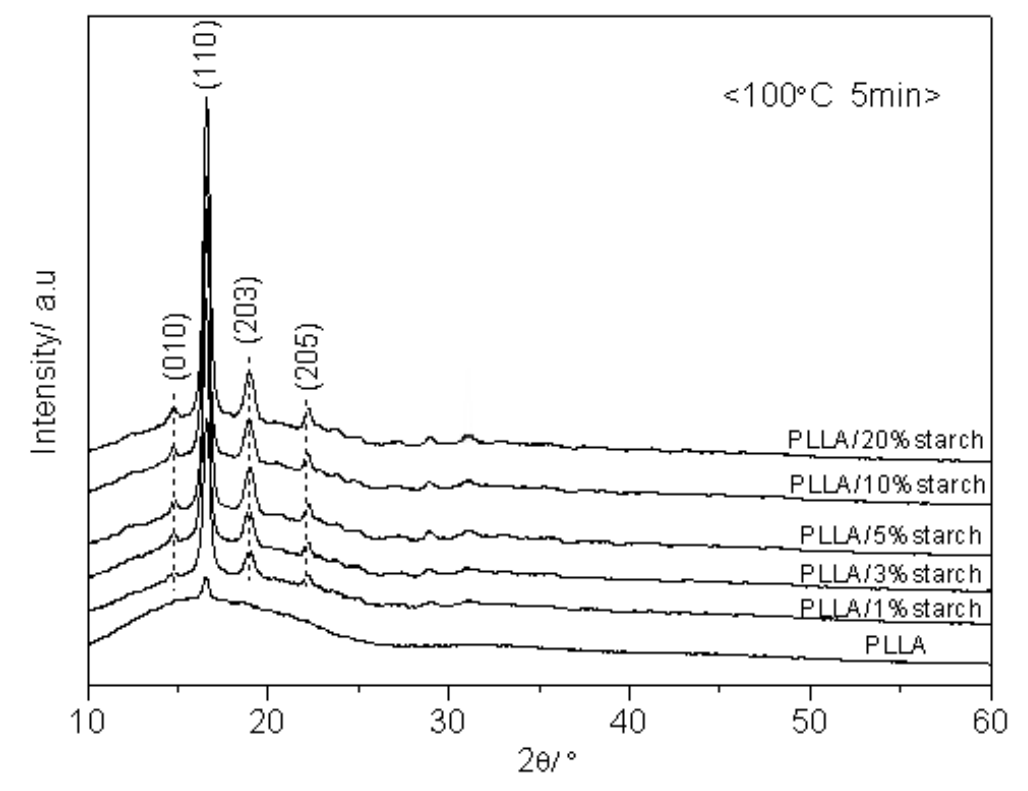

Fig. (5). XRD curves of PLLA and PLLA/starch after isothermal crystallization at $100{ }^{\circ} \mathrm{C}$ for $5 \mathrm{~min}$.

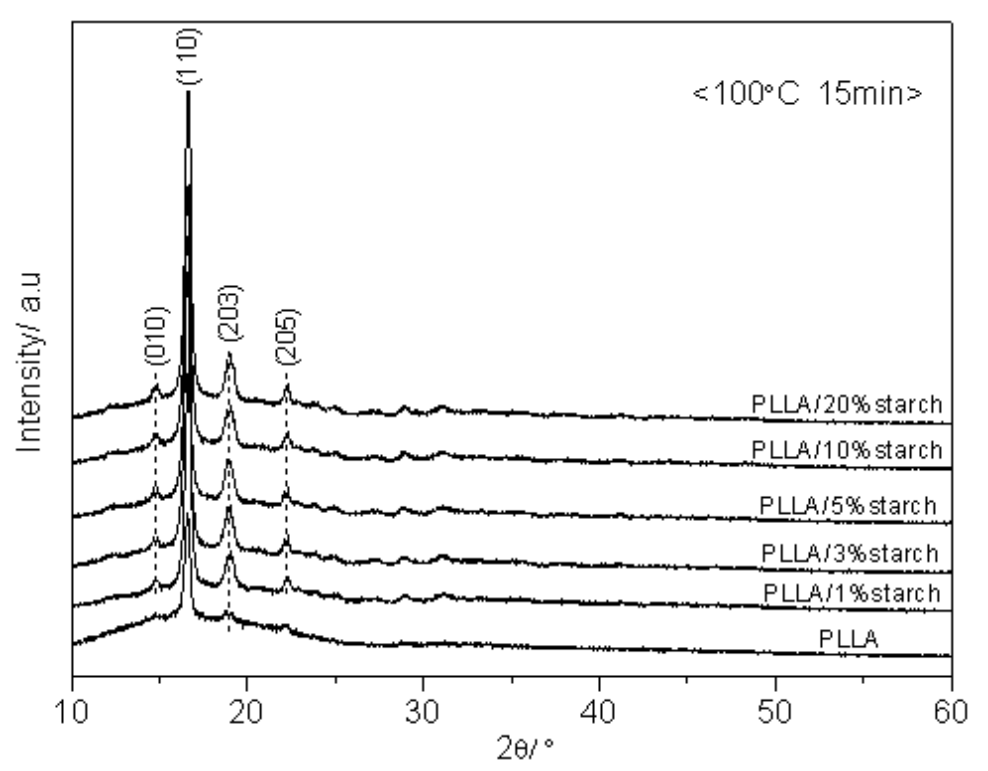

Fig. (6). XRD curves of PLLA and PLLA/starch after isothermal crystallization at $100{ }^{\circ} \mathrm{C}$ for 15 min.

\section{CONCLUSION}

Green PLLA/starch composites were fabricated by melt blending, and the fluidity and crystallization behavior of PLLA/starch were investigated; the kinetics of the isothermal crystallization of PLLA/starch composites was described 
using Avrami equation. The measurement results showed that the addition of starch could increase the fluidity and crystallization rate of PLLA significantly.

\section{ETHICS APPROVAL AND CONSENT TO PARTICIPATE}

Not applicable.

\section{HUMAN AND ANIMAL RIGHTS}

No Animals/Humans were used for studies that are base of this research.

\section{CONSENT FOR PUBLICATION}

Not applicable.

\section{CONFLICT OF INTEREST}

The author declares no conflict of interest, financial or otherwise.

\section{ACKNOWLEDGEMENTS}

This work was supported by National Natural Science Foundation of China (project number 51403027), Natural Science Foundation of Chongqing Municipal Science and Technology Commission (project number cstc2015jcyjBX0123), Scientific and Technological Research Program of Chongqing Municipal Education Commission (project number KJ1601101), and Innovation Team Project of Chongqing Municipal Education Commission (project number CXTDX201601037).

\section{REFERENCES}

[1] Yan SF, Yin JB, Yang Y, Dai ZZ, Ma J, Chen XS. Surface-grafted silica linked with L-lactic acid oligomer: A novel nanofiller to improve the performance of biodegradable poly(L-lactide). Polymer (Guildf) 2007; 48: 1688-94. [http://dx.doi.org/10.1016/j.polymer.2007.01.037]

[2] Xiong Z, Ma SQ, Fan LB, et al. Surface hydrophobic modification of starch with bio-based epoxy resins to fabricate high-performance polylactide composite materials. Compos Sci Technol 2014; 94: 16-22. [http://dx.doi.org/10.1016/j.compscitech.2014.01.007]

[3] Mucha M, Bialas S, Kaczmarek H. Effect of Nanosilver on the Photodegradation of Poly (lactic acid). J Appl Polym Sci 2014 ; 131 : 40144. [http://dx.doi.org/10.1002/app.40144]

[4] Pang MM, Pun MY, Chow WS, Ishak ZA. Carbon footprint calculation for thermoformed starch-filled polypropylene biobased materials. J Clean Prod 2014; 64: 602-8. [http://dx.doi.org/10.1016/j.jclepro.2013.07.026]

[5] Cerclé C, Sarazin P, Favis BD. High performance polyethylene/thermoplastic starch blends through controlled emulsification phenomena. Carbohydr Polym 2013; 92(1): 138-48 [http://dx.doi.org/10.1016/j.carbpol.2012.08.107] [PMID: 23218276]

[6] Witono JR, Noordergraaf IW, Heeres HJ, Janssen LP. Water absorption, retention and the swelling characteristics of cassava starch grafted with polyacrylic acid. Carbohydr Polym 2014; 103: 325-32.

[http://dx.doi.org/10.1016/j.carbpol.2013.12.056] [PMID: 24528736]

[7] Ferreira WH, Khalili RR, Figueira MJ, Andrade CT. Effect of organoclay on blends of individually plasticized thermoplastic starch and polypropylene. Ind Crops Prod 2014; 52: 38-45. [http://dx.doi.org/10.1016/j.indcrop.2013.10.016]

[8] Bie P, Liu P, Yu L, Li X, Chen L, Xie F. The properties of antimicrobial films derived from poly(lactic acid)/starch/chitosan blended matrix. Carbohydr Polym 2013; 98(1): 959-66.

[http://dx.doi.org/10.1016/j.carbpol.2013.07.004] [PMID: 23987434]

[9] Cai YH. Synthesis of $N$, N'-bis(benzoyl) azelaic acid dihydrazide and Its Effect on Performance of Poly(L-lactic acid). J Chem Soc Pak 2013; 35(4): 1174-8.

[10] Cai YH, Yan SF, Fan YQ, Yu ZY, Chen XS, Yin JB. The Nucleation Effect of $N$, $N^{\prime}$-Bis (benzoyl) Alkyl Diacid Dihydrazide on Crystallization of Biodegradable Poly (L-lactic acid). Iran Polym J 2012; 21(7): 435-44. [http://dx.doi.org/10.1007/s13726-012-0046-x]

[11] Park JW, Lee DJ, Yoo ES, Im SS, Kim SH, Kim YH. Biodegradable polymer blends of poly(lactic acid) and starch. Korea Polymer Journal 1999; 7(2): 93-101.

[12] Kang KS, Lee SI, Lee TJ, Narayan R, Shin BY. Effect of biobased and biodegradable nucleating agent on the isothermal crystallization of poly(lactic acid). Korean J Chem Eng 2008; 25(3): 599-608. 
[http://dx.doi.org/10.1007/s11814-008-0101-7]

[13] Hergeth WD, Lebek W, Stettin E, Witkowski K, Schmutzler K. Particle formation in emulsion polymerization, 2. Aggregation of primary particles. Makromol Chem 1992; 193(7): 1607-21.

[http://dx.doi.org/10.1002/macp.1992.021930705]

(C) 2017 Yan-Hua Cai.

This is an open access article distributed under the terms of the Creative Commons Attribution 4.0 International Public License (CC-BY 4.0), a copy of which is available at: (https://creativecommons.org/licenses/by/4.0/legalcode). This license permits unrestricted use, distribution, and reproduction in any medium, provided the original author and source are credited. 